\section{Intracranial tumour in an infant presenting as iron deficiency anaemia}

Anaemia is common in patients with malignant neoplastic disease' but is not generally recognised as a complication of brain tumours in the absence of vomiting or anorexia. We report the case of an infant who came to medical attention because of iron deficiency anaemia for which no cause was found until an intracranial neoplasm was diagnosed. The anaemia remained refractory to dietary iron supplements but resolved promptly after excision of the neoplasm.

\section{Case report}

The patient was admitted to hospital at the age of 10 months for investigation of anaemia. He was born of a full term normal delivery, smiled at 9 weeks, and sat unsupported at 6 months. Over the next four months, however, he became increasingly irritable and apathetic. The general practitioner noted anaemia, and comparison with previous records showed that he had not gained weight since the age of 7 months.

In hospital the child was found to be pale and miserable and his weight $(9.4 \mathrm{~kg})$ was just below the 50th centile. Head circumference was $49 \mathrm{~cm}$

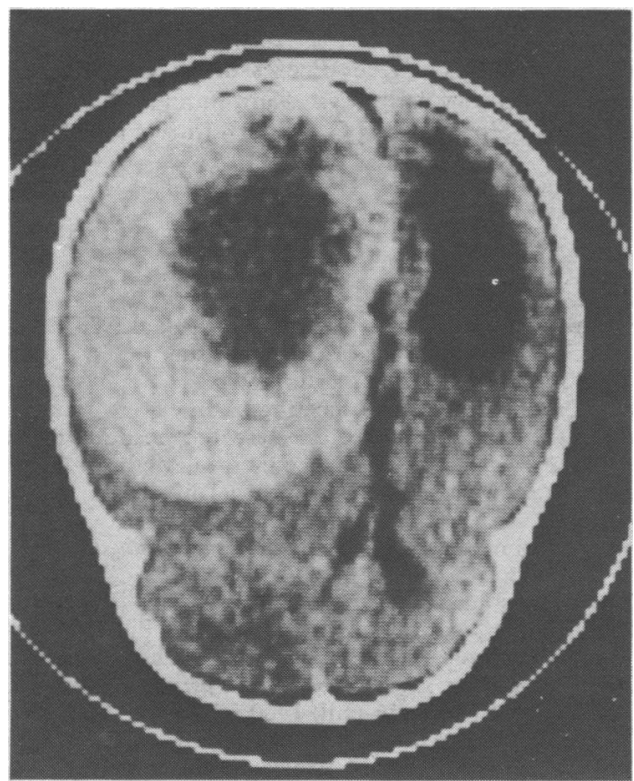

Contrast enhanced CT scan showing large tumour in occipital region, extending into temporal and parietal regions. Tumour has well defined edge and necrotic centre, was causing considerable mass effect, and had expanded right side of vault.

( $>90$ th centile), having been $34 \mathrm{~cm}$ ( $>50$ th centile) at birth, and the fontanelle was wide but slack. This was not considered relevant, as both the mother and her brother had constitutional macrocrania.

Haemoglobin concentration was $6.0 \mathrm{~g} / \mathrm{dl}$ and red cell indices reflected a microcytic hypochromic anaemia. Extensive haematological studies showed only deficiency of iron. Dietary assessment did not substantiate deficient intake of energy, protein, or iron, while results of three tests for occult blood and parasites in the stool, measurement of faecal fat, intravenous pyelography, and jejunal biopsy were all normal, as was an extensive infection screen. Iron supplements were begun but he failed to respond and did not mount a reticulocyte response. A skull radiograph showed suture diastasis.

At the time of admission to our unit he had been receiving iron supplements for eight weeks but still had a haemoglobin concentration of $6.2 \mathrm{~g} / \mathrm{dl}$. Weight was $10 \mathrm{~kg}$, head circumference $50 \mathrm{~cm}$, and there was obvious psychomotor retardation. Computed tomography showed a large, well defined mass with a necrotic centre occupying the posterior two thirds of the right hemicranium with considerable mass effect (figure). Angiography showed a large mass with a rich capillary circulation. He underwent craniotomy with complete macroscopic removal of a fibrillary astrocytoma grade 3 weighing $550 \mathrm{~g}$. The only detectable postoperative deficit was left homonymous hemianopia. Haemoglobin concentration began to rise after removal of the tumour and two weeks later was $12 \cdot 8 \mathrm{~g} / \mathrm{dl}$. He underwent a course of radiotherapy, and at six month follow up the haemoglobin concentration was $12 \mathrm{~g} / \mathrm{dl}$, mean cell volume $79 \mathrm{fl}\left(79 \mu \mathrm{m}^{3}\right)$, mean cell haemoglobin $25.1 \mathrm{pg}$, and mean cell haemoglobin concentration $31.7 \mathrm{~g} / \mathrm{dl}$. At 2 years he was thriving and reaching milestones normally.

\section{Comment}

Anaemia is the most important haematological disorder in malignancy and, while chronic blood loss or infection may sometimes be identified, in up to $60 \%$ of cases no clear cause emerges. ${ }^{1}$ The incidence of microcytic hypochromic anaemia in one series of patients with malignant disease was only $3 \%,{ }^{2}$ and its appearance in our patient was presumably due to sequestration of iron in a richly vascularised tumour undergoing central necrosis and representing (at the time of operation) $0.5 \%$ of the child's weight and $60 \%$ of the expected brain weight. Other causes of anaemia had been excluded by thorough investigation, and formal dietary assessment confirmed adequate intake of iron and protein. The lack of response to iron for eight weeks and resolution of the anaemia after removal of the tumour strongly suggest a causal relation.

The paucity of specific clinical features of brain tumours in infants hampers early diagnosis in many instances ${ }^{3}$ and our case shows that anaemia may be one such presentation. This makes CT scanning mandatory when macrocrania is also present in a child with nonneurological symptoms.

We thank Miss Sally Alden for help in preparing this manuscript.

${ }^{1}$ Miller A, Chodos RB, Emerson CP, Ross JF. Studies of the anemia and iron metabolism in cancer. 7 Clin Invest 1956 ;35:1248-52.

2 Banerjee JRN, Narang RM. Haematological changes in malignancy. Br $\mathcal{F}$ Haematol 1967;13:829-43.

${ }^{3}$ Farwell JR, Dohrmann GJ, Flannery JT. Intracranial neoplasms in infants. Arch Neurol 1978;35:533-7.

(Accepted 12 December 1983)

Department of Neurosurgery, Hospital for Sick Children, Great Ormond Street, London WC1

R JOOMA, FRCS, registrar

D N GRANT, FRCs, consultant

Correspondence to: Mr R Jooma, Department of Neurosurgery, Frenchay Hospital, Bristol BS16 1LE.

\section{Localised visceral immunocytoma associated with serological findings suggesting systemic lupus erythematosus}

Immunocytomas are tumours of plasmacytoid origin that have the ability to synthesise immunoglobulins. ${ }^{1}$ We describe two patients with the rare association of localised visceral immunocytoma, monoclonal gammopathy, and positive serological findings suggesting systemic lupus erythematosus.

\section{Case reports}

Case 1-A 50 year old woman was admitted because of prolonged fever. Eight years previously pancytopenia had been incidentally discovered, but physical examination at that time had been normal. She was followed up for two years, over which time her haemoglobin concentration was $11-13 \mathrm{~g} /$ dl, white cell count $2 \cdot 2-3 \cdot 6 \times 10^{9} / 1$ (normal differential), and platelet count $7 \cdot 5-120 \times 10^{9} / 1$. Electrophoresis of serum proteins yielded normal results, and serological tests for lupus erythematosus cells, antinuclear antibodies, and anti-DNA antibodies yielded negative results. She had remained 
asymptomatic until eight months before her present admission, when she began to experience weakness, weight loss, and a fever of $37 \cdot 5-38 \mathrm{C}$ and her liver, spleen, and several cervical lymph nodes became palpable. Serological examination showed lupus erythematosus cells, antinuclear antibodies in a titre of $1 / 1280$, and hypocomplementaemia of C3 $1 \mathrm{~g} / 1$ (normal range $0 \cdot 9-2 \cdot 0 \mathrm{~g} / \mathrm{l}$ ) and $\mathrm{C} 40-200 \mathrm{mg} / \mathrm{l}$ (normal range $300-600 \mathrm{mg} / \mathrm{l}$ ). A biopsy specimen showed a regularly shaped node with sarcoid-like granulomas. Results of other laboratory tests were unchanged except for the appearance of monoclonal gammopathy of IgG with $x$ chains. She underwent explorative laparotomy and splenectomy. The histopathological picture of the spleen was compatible with a diagnosis of polymorphic immunocytoma Chemotherapy was started, and 12 months after operation she was in full clinical remission and serological tests showed antinuclear antibodies in a titre of $1 / 128$ and lupus erythematosus cells.

Case 2-A 70 year old woman was admitted with dyspnoea, fever of $37.5^{\circ} \mathrm{C}$ of six weeks' duration, and recent weight loss of $15 \mathrm{~kg}$. Nine years previously a routine $x$ ray examination of her chest had shown a round lesion of her right lung. Serological tests for lupus erythematosus cells and antinuclear antibody had yielded negative results. These pathological findings were not investigated, and she had remained asymptomatic. Physical examination on admission showed pallor, dyspnoea, and dullness with loss of breathing sounds over the lower two thirds of the right lung. A chest radiograph showed that the right middle lobe was replaced by a large mass, and a moderate amount of pleural effusion was also present. Laboratory examination showed erythrocyte sedimentation rate $145 \mathrm{~mm}$ in first hou (Westergren), haemoglobin concentration $10 \mathrm{~g} / \mathrm{dl}$, white cell count $6.9 \times 10^{9} / 1$, platelet count $150 \times 10^{9} / 1$, total protein concentration $96 \mathrm{~g} / 1$, albumin $26 \mathrm{~g} / \mathrm{l}$, globulin $70 \mathrm{~g} / \mathrm{l}$. Electrophoresis of proteins showed a monoclonal gammopathy. Immunoglobulin concentrations were IgG $7.5 \mathrm{~g} / \mathrm{l}$ (normal range $6-16 \mathrm{~g} / \mathrm{l}$ ), $\mathrm{IgA} 0.6 \mathrm{~g} / \mathrm{l}$ (normal range $0.98-4.0 \mathrm{~g} / \mathrm{l}$ ), and $\mathrm{IgM} 410 \mathrm{~g} / \mathrm{l}$ (normal range $2 \cdot 7-2 \cdot 08 \mathrm{~g} / \mathrm{l}$ ). The $\mathrm{IgM}$ was characterised as being monoclonal with $\%$ light chains (figure). On ultracentrifugation the monoclonal IgM precipitated at $14 \mathrm{~S}$ instead of the usual $19 \mathrm{~S}$. Serological examinations showed lupus erythematosus cells and antinuclear antibodies in a titre of 1/1280. Anti DNA antibodies were not found. At thoracotomy a solid tumour of the right middle lobe was resected and defined as immunocytoma. The postoperative course was complicated by sepsis, and she died two weeks after surgery.

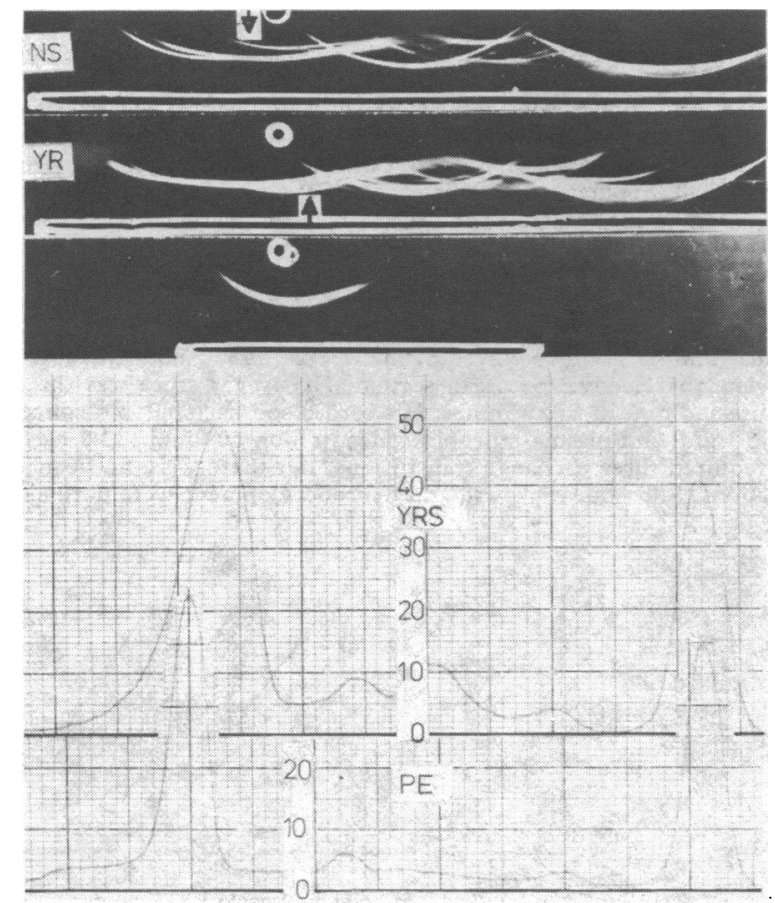

Results of serum protein immunoelectrophoresis in case 2 (YR) showing unusual localisation of IgM fraction (arrow) in comparison with that in normal serum (NS) (top); and electrophoretic pattern of serum (YRS) and pleural exudate (PE) in case 2 showing a similar monoclonal fraction in both fluids (bottom).

\section{Comment}

Immunocytoma usually affects the lymph nodes. This was the case in $240(81 \%)$ of a series of 296 patients. $^{2}$ In $130(44 \%)$ of the patients a serum monoclonal component was detected, which in most cases was of the IgM type; in the others it was found intracellularly. The paraprotein is usually of normal structure, but monoclonal monomers of IgM ( $7 \mathrm{~S}$ on ultracentrifugation) have occasionally been described in patients with macroglobulinaemia, systemic lupus erythematosus, cirrhosis of liver, and chronic infections. ${ }^{3}$ A light IgM was found in the serum of several patients with lymphoma, but the exact characteristics of this globulin were not defined. ${ }^{4}$ The IgM fraction in our second patient was identified as a partially polymerised molecule that, instead of having the normal pentameric configuration, was formed of dimers and trimers alone. This type of IgM has not been described previously.

In our two patients serological findings suggested that systemic lupus erythematosus had preceded the diagnosis of immunocytoma by years. To our knowledge these are the first reported cases of this association.

${ }^{1}$ Lennert K. Malignant lymphomas other than Hodgkin's disease. Berlin: Springer-Verlag, 1978:209-13.

'Lennert K. Malignant lymphomas other than Hodgkin's disease. Berlin: Springer-Verlag, 1978:223.

${ }^{3}$ Solomon A, Kunbel HG. A monoclonal type low molecular weight protein related to gamma-M-macroglobulin. Am $\mathscr{f}$ Med 1967;42 958-67.

${ }^{4}$ Ko HS, Pruzanski W. M components associated with lymphoma-a review of 62 cases. Am $\mathcal{F}$ Med Sci 1976;272:175-83.

(Accepted 16 December 1983)

Department of Internal Medicine "C," Beilinson Medical Centre,

Tel Aviv University Sackler School of Medicine, Israel

$S$ DUX, MD, senior resident

$S$ PITLIK, MD, deputy chief, lecturer

J B ROSENFELD, MD, professor of medicine

Division of Clinical Immunology, Beilinson Medical Centre

$\mathrm{J}$ PICK, MD, associate professor of medicine

Department of Pathology, Beilinson Medical Centre

$M$ BEN-BASSAT, MD, associate professor of pathology

Correspondence and requests for reprints to: Professor J B Rosenfeld.

\section{Does ethamsylate increase the incidence of venous thrombosis?}

Ethamsylate, a drug which increases capillary strength and reduces small vessel haemorrhage, has been shown to decrease blood loss in patients undergoing transurethral resection of the prostate ${ }^{1}$ It is also used to control menorrhagia. A study using the drug in vaginal surgery reported a significant increase in the incidence of postoperative deep vein thrombosis. ${ }^{2}$ That study was subsequently criticised $^{3}$ on the basis that more of the patients in the ethamsylate treated group than in the placebo group were obese or had received vasoconstrictive agents and several different surgeons had performed the operations. In addition, it was pointed out that "the incidence of $26 \%$ positive which was noted in the ethamsylate group corresponds to a figure of $29 \%$ positive which has been reported for a series of patients undergoing major gynaecological surgery"; and the most surprising fact was the total absence of deep vein thrombosis in the placebo group.

The following study was therefore undertaken to reassess any effect that ethamsylate might have on the incidence of postoperative deep vein thrombosis after vaginal surgery and on the amount of surgical blood loss and postoperative morbidity.

\section{Patients, methods, and results}

Fifty one patients undergoing vaginal hysterectomy for benign conditions were studied. Patients with a history of thrombosis or bleeding diathesis were excluded. None of the patients included in the study were receiving or had recently been treated with an oestrogen/progesterone preparation. The mean age of the 24 patients in the ethamsylate group was 56.5 years and of the 27 patients in the placebo group $57 \cdot 8$ years. Eight patients in the ethamsylate group and 10 in the placebo group were premenopausal. In addition to a vaginal hysterectomy, 20 patients in the ethamsylate group and 24 in the placebo group had a vaginal repair. The mean weight of patients in the ethamsylate group was $62.0 \mathrm{~kg}$ and of those in the placebo group 66.5 kg. Two patients in each group smoked cigarettes. Four patients in the ethamsylate group and five in the placebo group had varicose veins. There was thus no significant difference between the groups for any of these factors (Student's $t$ test and $\gamma^{2}$ test, as appropriate). 